\title{
Age-dependent decrease of polymeric Ig receptor expression and IgA elevation in ddY mice: a possible cause of IgA nephropathy
}

\author{
Takeshi Yanagihara ${ }^{1,2}$, Yoshihiro Kumagai ${ }^{1}$, Yoshihiko Norose ${ }^{1}$, Itaru Moro ${ }^{3}$, Masanobu \\ Nanno $^{4}$, Mutsumi Murakami ${ }^{2}$ and Hidemi Takahashi ${ }^{1}$ \\ ${ }^{1}$ Department of Microbiology and Immunology; ${ }^{2}$ Department of Pediatrics, Nippon Medical School, Tokyo, \\ Japan; ${ }^{3}$ Department of Pathology, Nihon University School of Dentistry, Tokyo, Japan and ${ }^{4}$ Yakult Central \\ Institute for Microbiological Research, Tokyo, Japan
}

\begin{abstract}
Individual animals in the closed colony population of ddY mice were analyzed to clarify the major cause of agedependent elevation of serum IgA and the appearance of human IgA nephropathy (IgAN)-like symptoms. Based on the serum IgA levels, the mice were classified into two subgroups. One was a high serum IgA group with some manifestations of IgAN through aging ( $\left(\mathrm{dd} Y^{\mathrm{High}}\right)$, and the other was a normal serum IgA group without IgAN (ddYNorm). The ratio of urinary $\operatorname{lgA}$ to serum $\operatorname{IgA}$ was significantly reduced in $\mathrm{dd}^{\mathrm{High}}$ mice, suggesting an impaired IgA clearance via secretion through the epithelial barrier. The actual clearance rate of the intravenously injected dimeric IgA in dd $Y^{\text {High }}$ mice was found to be slower than that in dd $Y^{\text {Norm }}$ mice. Furthermore, we found that the polymeric Ig receptors (plgRs) that mediate transcytosis of IgA were poorly expressed in the glomeruli as well as in the intestine of $\mathrm{dd}^{\mathrm{High}}$ mice, whereas the plgRs were more abundantly expressed in dd $Y^{\text {Norm }}$ mice. In addition, the comparative study using polymerase chain reaction showed that decreased plgR expression occurred at the transcriptional level in the $\mathrm{dd}^{\mathrm{High}}$ population. Taken together, these results suggest that a systemic defect in plgR expression may result in impaired IgA secretion and accumulation of $\operatorname{lgA}$ in the serum of dd $\mathrm{Y}^{\mathrm{High}}$ mice. The age-dependent changes of plgR expression in the dimeric IgA secretion sites of ddYHigh mice suggest a possible cause for the elevation of serum IgA level and the pathogenesis of IgAN-like disease.
\end{abstract}

Laboratory Investigation (2004) 84, 63-70, advance online publication, 20 November 2003; doi:10.1038/labinvest.3700012

Keywords: IgA nephropathy; plgR; ddY mice; RT-PCR; mucosal immunity

IgA nephropathy (IgAN) is probably the most common glomerular disease in the world, and is characterized by IgA deposition in the glomeruli, usually with serum IgA elevation. ${ }^{1}$ The progression of the disease is indicated by proliferation of mesangial cells and expansion of extracellular matrices. The pathological diagnostic finding of IgAN is determined by the intensity of IgA deposit in the mesangial area, which is usually associated with $\mathrm{C} 3$, properdin, factor $\mathrm{H}$, and membrane attack complex (C5b-9), but not with C4. ${ }^{2}$ Thus, the mesangial injury appears to be mediated by IgAassociated activation of complements in an alternate pathway correlating with the elevation of serum IgA,

Correspondence: Hidemi Takahashi, Department of Microbiology and Immunology, Nippon Medical School, 1-1-5 Sendagi, Bunkyo-ku, Tokyo 113-8602, Japan.

E-mail: htkuhkai@nms.ac.jp

Received 24 September 2003; accepted 02 October 2003; published online 20 November 2003 and the fate of IgA-based immune complexes must be a critical factor in the establishment of IgAN.

However, the actual pathogenesis of IgAN remains poorly understood, although a number of clinical and experimental studies have been reported so far. For example, elevated serum IgA has been shown among those who suffered from IgAN with IgA deposition in the glomeruli, and the major type of $\operatorname{IgA}$ in the sera and deposited $\operatorname{IgA}$ among these patients have been identified as polymeric IgA (pIgA). ${ }^{3,4}$ This pIgA should instead have been secreted via mucosal barrier to form a complex with secretory components (SCs) produced by epithelial tissues. SCs are the processed portion of polymeric Ig receptor (pIgR) molecules, which should control the secretion of pIgA. ${ }^{5,6}$ Shimada $e t a I^{7}$ have recently established pIgR knockout $\left(\mathrm{pIgR}^{-1-}\right)$ mice and described that these mice had a high serum pIgA concentration due to the interruption of transepithelial transport of pIgA. Therefore, we focused on the defects of IgA secretion, especially by the pIgRsecretion system, as a cause of serum IgA elevation. 
In the present study, we first quantified serum and urinary IgA concentrations every 4 weeks to identify aged ddY mice showing high serum IgA (HIGA) with relatively low urinary IgA. ${ }^{8}$ We found that we could classify ddY mice into at least two subgroups. One was a HIGA group that exhibited some symptoms of IgAN through aging ( $\left.d d \mathrm{Y}^{\mathrm{High}}\right)$, and the other was a

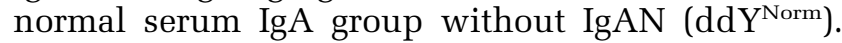
Moreover, taking advantage of dimeric IgA carrying allotypic markers (Igh-2b), we confirmed that the actual clearance rate of the intravenously injected dimeric IgA in $d d \mathrm{Y}^{\mathrm{High}}$ mice was slower than that in dd $Y^{\text {Norm }}$ mice. Then, we compared the pIgR expression in the kidney as well as the small intestine between those two groups by immunofluorescence staining and reverse transcription polymerase chain reaction (RT-PCR), to clarify the relationship between the expression of pIgR in mucosa and the appearance of IgAN in ddY mice.

\section{Materials and methods}

\section{Mice}

In all, 10 female BALB/c mice, C57BL/6 and 26 female ddY mice at 11 weeks old were purchased from Japan SLC (Shizuoka, Japan). The female ddY mice were selectively used because of their longlived nature compared to male mice, and the phenotype of IgA elevation through aging is independent of the sex. The mice were maintained in specific pathogen-free conditions and fed autoclaved food and water. All mice were cared for according to the guidelines of the NIH Guide for the care and use of laboratory animals.

\section{Enzyme-Linked Immunosorbent Assay for Serum, Urinary, and Fecal IgA}

Blood, urine, and feces of each mouse were collected at 4-week intervals between 12 and 44 weeks of age. Blood samples were obtained from the tail vein, and the serum was prepared, frozen immediately, and stored at $-80^{\circ} \mathrm{C}$ until the analysis. The urine samples were collected directly to sample tubes by tenderly pushing their abdomen. They were centrifuged at $400 \mathrm{~g}$ and the supernatant was stocked at $-80^{\circ} \mathrm{C}$ until the analysis. Four to five fecal pellets from each mouse were collected into preweighed Eppendorf tubes. Fecal weight was calculated by subtracting the preweight values. PBS $(1 \mathrm{ml})$ was added per $100 \mathrm{mg}$ of feces. Samples were vortexed until all materials were dispersed, settled at room temperature for $15 \mathrm{~min}$, and then centrifuged at $13000 \mathrm{rpm}$ for $15 \mathrm{~min}$. The supernatant was removed and stored at $-80^{\circ} \mathrm{C}$ for analysis. Serum, urinary, and fecal IgA concentrations were measured by modified sandwich Enzyme-linked immunosorbent assay (ELISA), as described previously. ${ }^{9}$ Briefly, polystyrene micro- titer plates (Nunc-Immuno Plate; Nalge Nunc International, Rochester, NY, USA) were coated with goat anti-mouse IgA antibody (Cappel Laboratories, Durham, NC, USA). After washing with 1\% BSA-PBS three times, the sera, urine, or fecal samples were added at 1:100, 1:20, or 1:40 dilution. The bound IgA molecules were detected with biotin-conjugated rat anti-mouse IgA antibodies (BD Pharmingen, San Diego, CA, USA), followed by incubation with horseradish peroxidase-conjugated avidin D. The substrate, 2,2'-azino-bis(3-ethylbenzthiazoline6-sulfonic acid) (Sigma-Aldrich, St Louis, MO, USA), was used for color development, and the absorbance at $415 \mathrm{~nm}$ was measured for quantification. The net quantities of IgA were determined using the standard curve obtained from the mouse IgA proteins (MOPC315, Cappel).

\section{Purification and Molecular Analysis of Serum IgA}

The composition and qualitative differences of serum IgA molecules were analyzed by reducing and nonreducing sodium dodecyl sulfate polyacrylamide gel electrophoresis (SDS-PAGE) on 2/15\% gradient polyacrylamide gels (Multigel; Daiichi Pure Chemicals Co., Ltd, Tokyo, Japan). The serum IgA was purified with anti-mouse IgA antibody (Cappel)-conjugated CNBr-activated Sepharose 4B beads and Sephadex G25 column described in affinity chromatography (Amersham Pharmacia Biotech, Uppsala, Sweden). The location of monomeric and dimeric IgA molecules were reconfirmed by Western blotting using biotin-labeled rat anti-IgA antibodies and peroxidase-labeled avidin D. Silver Staining Kit (Amersham Pharmacia Biotech) was used for staining of proteins.

The dimeric IgA molecules of Igh-2b allotype derived from $\mathrm{C} 57 \mathrm{Bl} / 6$ mouse sera were prepared from the affinity-purified IgA monomer and dimer mixtures as follows. First, the dimers were separated by nonreducing $2 / 15 \%$ gradient PAGE. Second, the gel regions containing dimeric IgA were cut off and the dimer molecules were electro-eluted and renaturated by dialyzing against $\mathrm{PBS}$ at $4^{\circ} \mathrm{C}$ for 3 days.

\section{Intraveneous Administration of Dimeric IgA and Analysis of the Clearance by ELISA}

A total of $20 \mu \mathrm{g}$ of purified dimeric IgA of the b allotype (Igh-2b) in $0.5 \mathrm{ml}$ of PBS was intravenously injected into $d d Y^{\text {High }}$ and dd ${ }^{\text {Norm }}$ mice, which do not have the genotype of Igh-2b and whose IgAs do not react to monoclonal anti-Igh-2b antibodies (data not shown). Blood samples of $20-50 \mu \mathrm{l}$ of blood was collected from the tail vein of each mouse at 1, 6, 12, $24,36,48,60,72,84$, and $96 \mathrm{~h}$ after the intravenous administration of Igh-2b at 44 weeks old of age. The amount of Igh-2b protein was selectively measured by utilizing the specific reactivity of the monoclonal anti-Igh-2b antibody (HIS-M2, BD Pharmingen) to 
the allotypic determinants of IgA molecules. The details of the measurement have been described in the ELISA section above, except that the purified monoclonal anti-Igh-2b antibodies $(10 \mu \mathrm{g} / \mathrm{ml}$ in PBS) were used to coat the plates in the first step. This system allows us to examine the fate of administered IgA (Igh-2b) molecules selectively at high sensitivity without the need for radiolabeled or chemically modified IgA proteins. The statistical significance was scored according to Turkey's Student's $t$-test. The predetermined upper limit of probability for statistical significance was $P<0.01$.

\section{Histological and Immunofluorescent Analysis}

All mice were killed at 44 weeks of age, and the kidneys and the small intestines were removed and trimmed off the fat and connective tissues. Some of them were treated by standard paraformaldehyde fixation protocol for histological staining, and the others were placed in an embedding compound (TISSUE MOUNT; Chiba Medical, Saitama, Japan), and snap-frozen on dry ice and ethanol for immunofluorescent analysis. Tissue injury was assessed by hematoxylin-eosin (HE) staining and periodic acidSchiff (PAS) staining. To detect pIgR expression and IgA deposition, each frozen section $(6 \mathrm{~mm}$ thickness) was fixed with cold acetone for $10 \mathrm{~min}$, incubated with $1 \%$ BSA and $10 \%$ goat serum at $4{ }^{\circ} \mathrm{C}$ overnight and with Avidin/Biotin Blocking Kit (Vector Laboratories, Burlingame, CA, USA). Subsequently, the specimens were labeled with rabbit anti-mouse SC $\operatorname{IgG}^{7}(5 \mu \mathrm{g} / \mathrm{ml})$ for the kidney or rabbit anti-mouse SC serum ${ }^{10}$ (1:150) for the small intestine, or rat anti-mouse IgA antibody $(1 \mu \mathrm{g} / \mathrm{ml})$ (BD Pharmingen) for $1 \mathrm{~h}$ at $37^{\circ} \mathrm{C}$. Finally, fluorescein isothiocyanate (FITC)-conjugated anti-rabbit Ig (1:200) (BD Pharmingen), or biotin-conjugated antirat IgG (1:200) (Cedarlane Laboratories, Hornby, Ontario, Canada) was added for $30 \mathrm{~min}$ at $37^{\circ} \mathrm{C}$ and FITC-conjugated streptavidin (1:2000) (BD Pharmingen) was added for $10 \mathrm{~min}$ at room temperature. The staining pattern was analyzed by using Confocal Laser Scope (LSM510; Carl Zeiss, Jena, Germany).

\section{RT-PCR for pIgR mRNA in the Kidney and the Small Intestine}

Total RNA was extracted from the renal cortex and the small intestine of ddY mice at 44 weeks old, from mouse pIgR transfectant cell (2S9.1). and from mock transfectant cells (3N.1) ${ }^{10}$ using the RNeasy Protect Mini Kit (Qiagen, Valencia, CA, USA) according to the manufacturer's instruction. RNA $(2 \mu \mathrm{g})$ was reverse transcribed with oligo-(dT)18 (Perkin Elmer, Wellesley, USA) priming and Superscript III (Invitrogen, Sandiego, USA) reverse transcriptase in a $20 \mu \mathrm{l}$ reaction mixture at $50^{\circ} \mathrm{C}$ for $60 \mathrm{~min}$. A measure of $1 \mu \mathrm{l}$ (equal to about $200 \mathrm{ng}$ ) of the cDNA product was then subjected to 40 cycles of PCR amplification consisting of $1 \mathrm{~min}$ at $95^{\circ} \mathrm{C}, 2 \mathrm{~min}$ at $55^{\circ} \mathrm{C}$, and $2 \mathrm{~min}$ at $72^{\circ} \mathrm{C}$ with a $7 \mathrm{~min}$ final extension at $72^{\circ} \mathrm{C}$, with a thermocycler (PCR Express; Hybaid, Teddington, Middlesex, UK). The amplification was performed in a reaction volume of $20 \mu \mathrm{l}$ with LA PCR buffer (Takara, Shiga, Japan), $2.5 \mathrm{mM} \mathrm{MgCl}_{2}, 0.3 \mathrm{mM}$ each deoxynucleotide triphosphate, $2.5 \mathrm{mM}$ of each primer, and $1 \mathrm{U}$ of LA Taq polymerase (Takara). The following oligonucleotide primers for pIgR and GAPDH are designed from published cDNA sequence: ${ }^{7} \mathrm{pIgR}$ senseprimer $\left(5^{\prime}-\right.$ TTCCTGAGTTGCCGAGTGACA- $3^{\prime}$, the beginning of the exon 4) and antisenseprimer (5'-CTAGGC TTCCTGGGGACCATC- $3^{\prime}$, the end of the exon 11); GAPDH senseprimer (5'-GCCTCAAGATCATCAGCAATGC-3') and antisenseprimer (5'-ATGCCAGT GAGCTTCCCGTTC-3').

\section{Results}

\section{Age-Dependent Changes of Serum and Urinary IgA Levels}

We examined the age-dependent changes of serum IgA concentration among $\mathrm{ddY}$ and BALB/c mice. Although the serum IgA levels of BALB/c mice did not increase and stayed close to the mean of $13 \mu \mathrm{g} /$ $\mathrm{ml}$ until 44 weeks of age (Figure 1A), the ddY mice population appeared to be segregated into at least two groups based on the serum IgA concentration. One was the $d d Y^{\text {High }}$ mice population that showed serum IgA concentrations two standard deviations (s.d.s) beyond the mean of control BALB/c mice. The other was the dd $Y^{\text {Norm }}$ mice population with the IgA level within the mean \pm 2 s.d.s of BALB/c mice throughout the whole course of the experiment. This result was consistent with the genetic segregation analysis observed in the closed-colony ddY population carried out by Imai et al. ${ }^{8}$

Next, we studied the age-dependent changes of urinary IgA concentration in ddY mice. Although we could also observe the elevation of IgA in urine among dd $\mathrm{Y}^{\mathrm{High}}$ mice to some extent, the magnitude of age-dependent IgA increase in urine was very low. Thus, we plotted the scatter diagram between urine and serum IgA levels at 24 weeks old (Figure1B; a and b) and 44 weeks old (Figure 1B; c and d) of those two segregated ddY mice. As indicated in Figure 1B, while the slopes of the regression curve in $\mathrm{dd} \mathrm{Y}^{\mathrm{Norm}}$ mice at 24 and 44 weeks old were 0.172 and 0.160 (a and c), those in dd $\mathrm{Y}^{\mathrm{High}}$ mice at correspondent weeks were 0.110 and 0.059 (b and d), respectively. These results show that the urine/serum IgA ratios in $\mathrm{ddY}^{\mathrm{High}}$ mice are lower than that in $\mathrm{ddY}^{\mathrm{Norm}}$ mice at 24 weeks of age and that they further decrease through aging. The relatively low level of urine IgA in $\mathrm{dd} \mathrm{Y}^{\mathrm{High}}$ mice may suggest the decrease in the efficacy of serum IgA transportation to the urinary tracts in an age-dependent manner. 
A

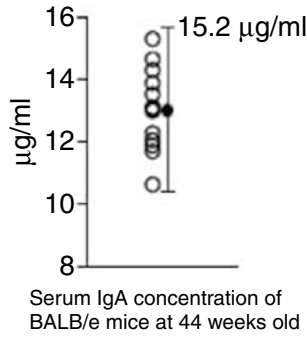

B
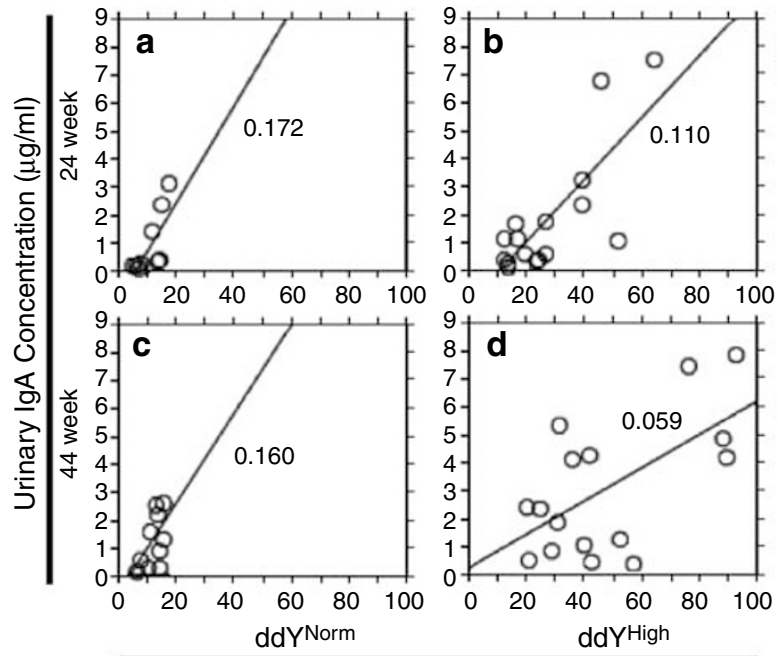

Serum IgA Concentration $(\mu \mathrm{g} / \mathrm{ml})$

Figure 1 Serum and urinary IgA. (A) Serum IgA concentrations of BALB/c mice at 44 weeks old. The maximal level of the serum IgA in $\mathrm{BALB} / \mathrm{c}$ mice was $15.2 \mu \mathrm{g} / \mathrm{ml}$. We referred the mean $(13.0 \mu \mathrm{g} / \mathrm{ml}) \pm$ two standard deviations (s.d.s) as the normal level of serum IgA for further experiments. (B) Correlation between urinary and serum IgA level of ddY ${ }^{\text {High }}$ and ddY ${ }^{\text {Norm }}$ mice at 24 weeks old (a and b) and 44 weeks old (c and d), respectively. The slopes of regression curve of ddY ${ }^{\text {Norm }}$ mice at 24 and 44 weeks old were almost unchanged as 0.172 and 0.160 (a and $\mathbf{c}$ ), while those of ddY $\mathrm{Y}^{\mathrm{High}}$ mice declined as 0.110 and 0.059 (b and $\mathbf{d}$ ), respectively. Consequently, ddY mice were classified into two populations according to their serum IgA level, and we confirmed that the rate of urinary to serum IgA level of ddYHigh mice decreased through aging compared with that of dd $\mathrm{Y}^{\mathrm{Norm}}$ mice.

Since the small intestine was known to be one of the major IgA-secreting organs, we also examined the amount of IgA in the feces of $d d Y^{\text {High }}$ mice by plotting the scatter diagram between feces and serum IgA levels. The results were similar to that found in urine (data not shown). These data suggest that $d d Y^{\text {High }}$ mice may have an age-dependent deficiency of systemic IgA secretion through mucosa.

\section{pIgR Expression in the Kidney and the Small Intestine}

To gain an insight into the defect of IgA secretion observed in dd $\mathrm{Y}^{\mathrm{High}}$ mice, the $\mathrm{pIgR}$ expression was compared between $\mathrm{dd} \mathrm{Y}^{\mathrm{High}}$ and $\mathrm{dd} \mathrm{Y}^{\mathrm{Norm}}$ mice. The specimens from dd $\mathrm{Y}^{\mathrm{High}}$ and $d \mathrm{~d}^{\mathrm{Norm}}$ kidneys were stained with FITC-labeled anti-pIgR polyclonal antibodies. Figure 2a and b shows the pIgR expression by FITC, and Figure 2c and d show the localization of the glomeruli in PAS staining. While both the glomeruli and the tubules of ddY $\mathrm{Y}^{\mathrm{Norm}}$ mice expressed pIgR (Figure 2a and c), the glomeruli in dd $\mathrm{Y}^{\text {High }}$ mice did not express a detectable level of pIgR and only a marginal expression was observed in the tubules (Figure $2 \mathrm{~b}$ and $\mathrm{d}$ ). The results suggest that the elevation of serum IgA may correlate with the decrease of pIgR in the kidney.

We also investigated pIgR expression in the guts of $d d Y^{\text {High }}$ and ddY $\mathrm{Y}^{\mathrm{Norm}}$ mice. Decreased pIgR expression in the intestinal epithelial cells at the tip of the villi was noted in $d d Y^{\text {High }}$ mice (Figure $3 b$ ), as compared with dd $\mathrm{Y}^{\mathrm{Norm}}$ mice (Figure 3a). This

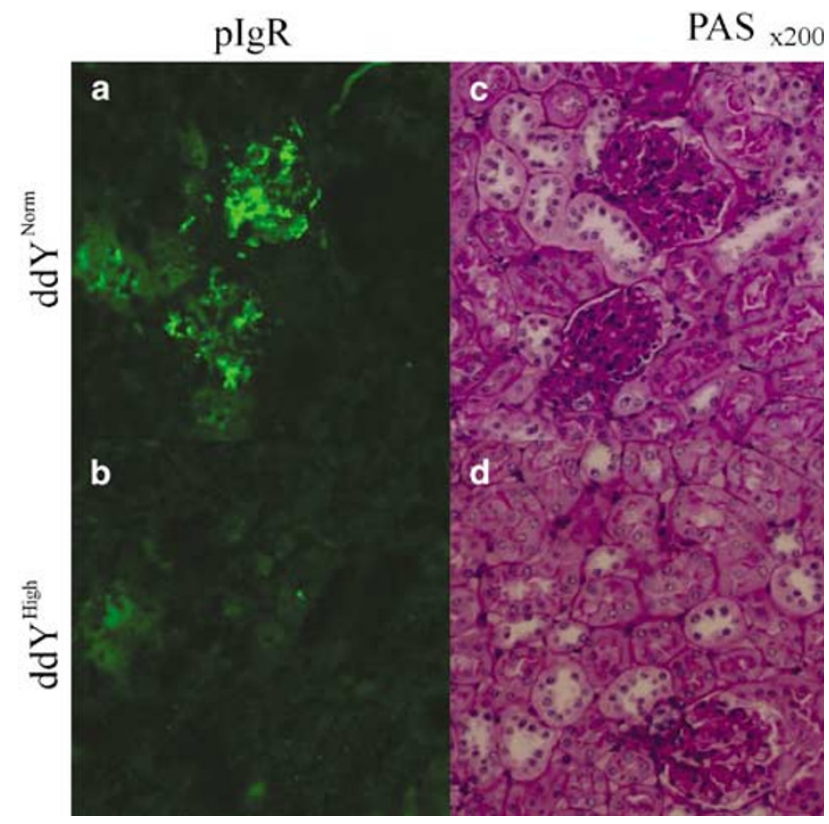

Figure 2 pIgR expression in the kidney. (a and b) The pIgR expression stained by FITC. (c and d) The localization of the glomeruli in PAS staining. The upper figures show the kidney of dd $Y^{\text {Norm }}$ mice at 44 weeks, and the bottom figures show those of dd $Y^{\text {High }}$ mice. The magnification is $200 \times$. We could observe $\mathrm{pIgR}$ expression in the glomeruli in $d d Y^{N o r m}$ mice, but not in $d d Y^{\text {High }}$ mice.

observation in the gut was parallel to the decreased expression of $\mathrm{pIgR}$ in dd $\mathrm{Y}^{\mathrm{High}}$ kidney. It was likely that the decrease of pIgR expression in $d d \mathrm{Y}^{\mathrm{High}}$ mice occurred systemically. 

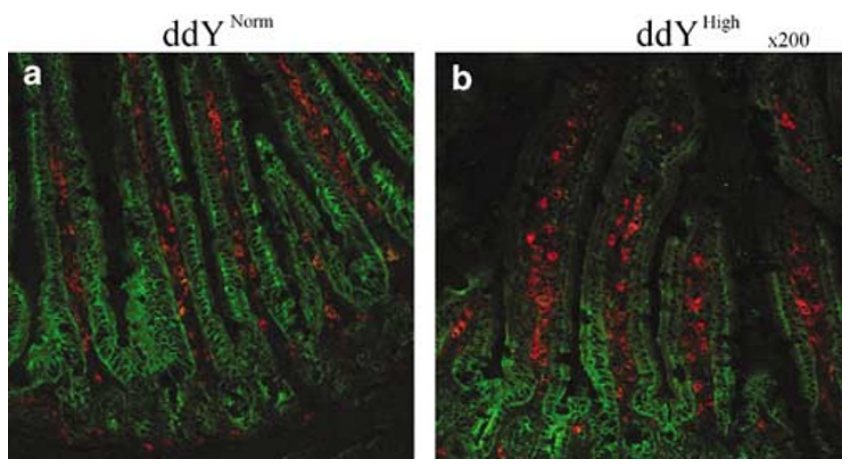

Figure 3 pIgR expression in the small intestine. (a and $\mathbf{b})$ The pIgR expression with FITC and surface IgA positive B cells with Texas-Red. (b) It shows decreased pIgR expression in the intestinal epithelial cells at the tip of the villi in ddYHigh mice compared with dd $\mathrm{Y}^{\mathrm{Norm}}$ mice (a). This observation is consistent with the decreased pIgR expression in the ddY ${ }^{\text {High }}$ kidney. Thus, the decrease of pIgR expression in dd $\mathrm{Y}^{\text {High }}$ mice may be the systemic symptom.

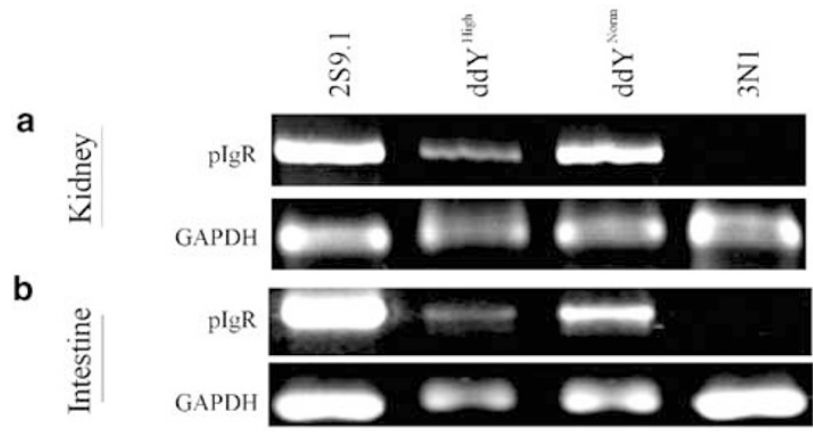

Figure 4 RT-PCR analysis of pIgR mRNA expression in the kidney (a) and the small intestine (b). The mRNA was prepared and analyzed as described in section Materials and methods. mRNA expression (a) in the kidney and (b) in the small intestine. The lane 2S9.1 represents amplified pIgR mRNA of pIgR-transfected cell as a positive control, and the lane $3 \mathrm{~N} 1$ shows that of mocktransfected cells as a negative control. The GAPDH product was shown at counter part of each figure as an internal control. The lane $d d Y^{\text {High }}$ and $d d Y^{\text {Norm }}$ showed the amplified PIgR mRNA of each kidney and small intestine. The pIgR mRNA expression of $d d Y^{\text {High }}$ mice was lower than that of dd $\mathrm{Y}^{\mathrm{Norm}}$ mice compared with the density of GAPDH.

\section{pIgR mRNA Expression in the Kidney}

To further support the difference in pIgR protein expression in $\mathrm{dd}^{\mathrm{High}}$ and in $\mathrm{dd} \mathrm{Y}^{\mathrm{Norm}}$ mice, $\mathrm{pIgR}$ mRNA transcription was also compared using semiquantitative RT-PCR analysis. The expression of pIgR mRNA in both the kidney and the small intestine of dd $\mathrm{Y}^{\mathrm{High}}$ mice were lower than in those of dd $Y^{\text {Norm }}$ mice (Figure 4a and b) compared with an internal control mRNA (GAPDH). Thus, the pIgR expression was confirmed to decrease in the kidney as well as in the small intestine of $d d \mathrm{Y}^{\mathrm{High}}$ mice. These results are consistent with the lower expression assessed by immunofluorescent staining.

\section{Composition and Qualitative Differences of IgA Molecules in Sera}

To examine the qualitative differences of serum IgA molecules between $\mathrm{dd} \mathrm{Y}^{\mathrm{High}}$ and $\mathrm{dd} \mathrm{Y}^{\mathrm{Norm}}$ mice, affinity-purified serum IgA proteins were run on 2/ $15 \%$ gradient SDS-PAGE under nonreducing conditions, followed by silver staining. The apparent molecular differences were not detected in terms of the ratio of monomeric IgA to dimeric IgA in $d d Y^{\text {High }}$ mice at 12 and 44 weeks of age (Figure 5). Also, molecular abnormalities of heavy and light chains of serum IgA molecules in $d d Y^{\mathrm{High}}$ and $d d \mathrm{Y}^{\mathrm{Norm}}$ mice were not detected by SDS-PAGE analysis under reducing conditions (data not shown). These results ruled out the possibility that the structural abnormality of IgAs in the sera of dd $\mathrm{Y}^{\mathrm{High}}$ mice influences the efficacy of IgA clearance in mucosa.

\section{Clearance of Dimeric IgA Molecules Following the Intravenous Administration to $\mathrm{dd}^{\mathrm{High}}$ and $\mathrm{dd}^{\mathrm{Norm}}$ Mice}

A total of $20 \mu \mathrm{g}$ of purified dimeric IgA of the b allotype (Igh-2b) was injected intravenously into the tail vein of aged $d d Y^{\text {High }}$ and $d d Y^{N o r m}$ mice having the different genotype of IgA from Igh-2b. After administration, serum Igh-2b concentrations were determined using ELISA at the intervals shown in the horizontal axis (Figure 6). Although the clearance rate of administrated dimeric IgA (Igh-2b) among $d d Y^{\text {High }}$ and $d d Y^{\text {Norm }}$ did not change at the early phase of clearance, a significant slow clearance rate was observed in $\mathrm{dd} \mathrm{Y}^{\mathrm{High}}$ compared to $\mathrm{dd} \mathrm{Y}^{\mathrm{Norm}}$ $(P<0.01)$ at the later phase (more than $24 \mathrm{~h}$ after dimeric Igh-2b IgA administration). The finding that the IgA secretion equilibrium in $d d \mathrm{Y}^{\mathrm{High}}$ was shifted to the lower rate suggests the systemic decrease of pIgR expression in the mucosal surface.

\section{Histological and Immunofluorescent Analysis}

The tissue sections of the kidneys from $d d Y^{H i g h}$ and dd $\mathrm{Y}^{\mathrm{Norm}}$ mice were stained by HE staining (data not shown) and PAS staining (Figure $7 \mathrm{a}$ and $\mathrm{b}$ ). Figure 7a shows a representative PAS staining of one of dd $\mathrm{Y}^{\text {High }}$ mice. It shows the diffuse mesangial hypercellularity, mesangial PAS-positive deposits, 


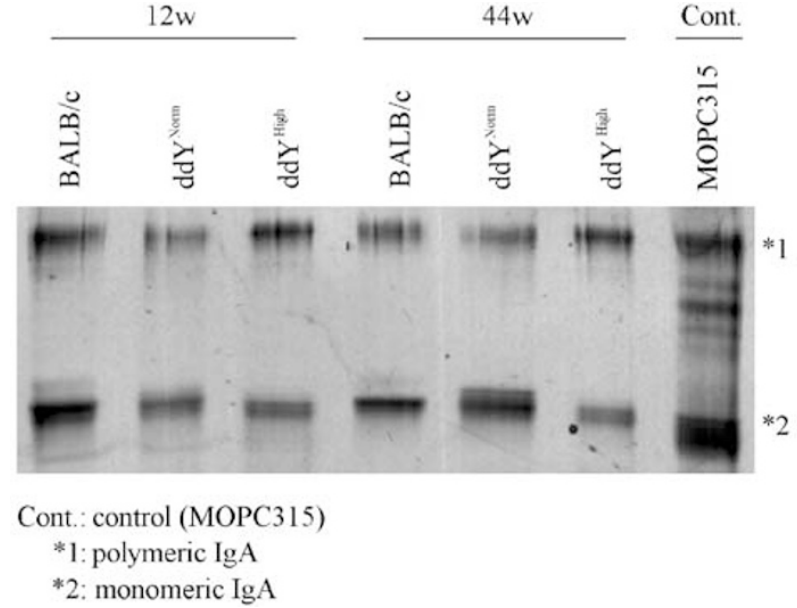

Figure 5 Qualitative differences of $\operatorname{IgA}$ molecules in sera. Affinity-purified serum IgA samples were applied to $2 / 15 \%$ gradient SDS-PAGE under nonreducing conditions, followed by silver staining. Serum IgA of BALB/c, dd $\mathrm{Y}^{\mathrm{Norm}}$ and $d d \mathrm{Y}^{\mathrm{High}}$ mice at 12 and 44 weeks old were applied. The apparent molecular and structural differences were not observed in terms of the proportion of monomeric IgA vs dimeric $\operatorname{IgA}$ in $d d \mathrm{Y}^{\text {High }}$ mice when compared with control murine IgA (MOPC315 clone). Thus, the possibility that the molecular abnormality of IgA in the sera was ruled out.

and matrix proliferation, which were typical appearances for IgAN. In contrast, as shown in Figure 7b, dd $\mathrm{Y}^{\mathrm{Norm}}$ mice showed no apparent abnormality in the kidneys. The HE staining revealed compatible results as detected by PAS staining (data not shown).

Figure 8a and b show IgA deposition in the glomeruli of $d d Y^{\text {High }}$ mice and $d d Y^{\text {Norm }}$ mice, respectively. The IgA deposition pattern in the glomeruli of ddY ${ }^{\mathrm{High}}$ mice was granular, which is compatible with that of IgAN. On the other hand, the IgA deposition in the glomeruli of $d d Y^{N o r m}$ mice was not predominant. These histological and immunofluorescent findings show that the decrease of pIgR might be responsible for IgA deposition in the glomeruli of dd $\mathrm{Y}^{\mathrm{High}}$ mice.

\section{Discussion}

By measuring the age-dependent changes of serum IgA level and IgA excretion profiles of ddY mice, we could classify the closed-colony population of ddY mice into at least two groups. In the $d d Y^{\text {High }}$ population, the age-dependent elevation of serum $\operatorname{IgA}$ and the relatively lower excretion of secretary IgA into urinary fluid and feces were observed. The ddY $\mathrm{Y}^{\mathrm{Norm}}$ population exhibited a steady level of serum IgA and relatively higher excretion of secretary IgA into urine and feces. Imai et $a l^{8}$ reported the genetic segregation of the ddY population into two groups with different criteria of IgA elevations. By selective breeding, Miyawaki et al ${ }^{11}$ established the HIGA mouse strain, which has the HIGA level and the IgAN-like manifestations. The $d d Y^{\text {High }}$ popula-

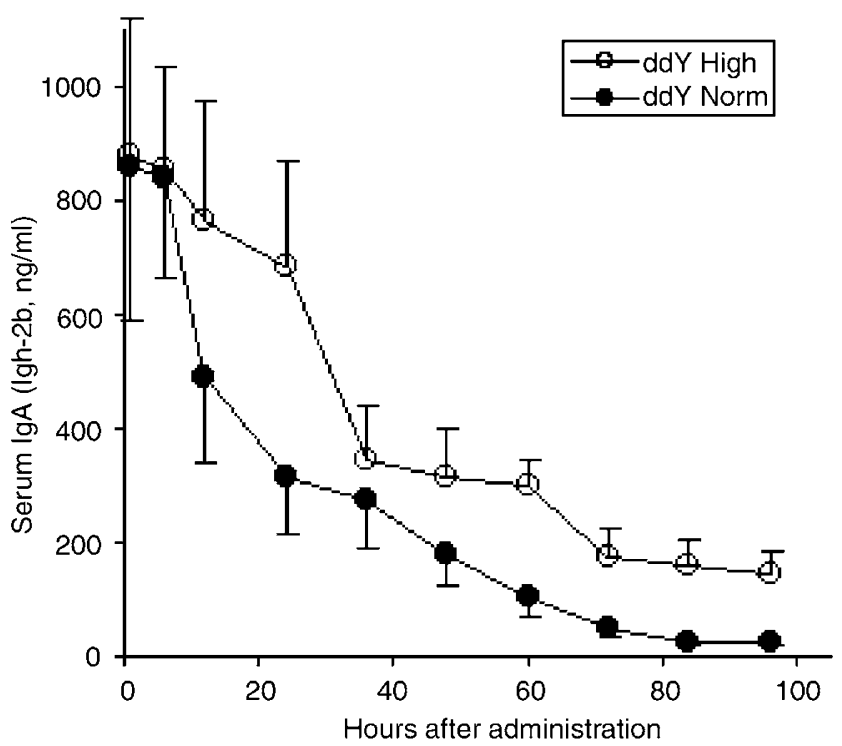

Figure 6 Clearance of dimeric IgA molecules following the intravenous administration to $d d \mathrm{Y}^{\mathrm{High}}$ and $d d \mathrm{Y}^{\mathrm{Norm}}$ mice. A total of $20 \mu \mathrm{g}$ of purified dimeric IgA of the b allotype (Igh-2b) was intravenously injected into the tail veins of dd $\mathrm{Y}^{\mathrm{High}}$ and $\mathrm{dd} \mathrm{Y}^{\mathrm{Norm}}$ mice having the different genotype of IgA from Igh-2b. After the administration, the serum Igh-2b concentration was determined using ELISA at the intervals shown in the horizontal axis. The line plotted by dot open circles and by filled circles show the profiles of $d d Y^{H i g h}$ and $d d Y^{\text {Norm }}$ mice respectively. The results represent the mean \pm standard error of three independent experiments ( $n=3$ at each experiment). The statistical significance was scored according to Turkey's Student's $t$-test. A significant difference $(P<0.01)$ between $\mathrm{dd} \mathrm{Y}^{\mathrm{High}}$ and $\mathrm{dd} \mathrm{Y}^{\mathrm{Norm}}$ was detected at $24,60,72,84$, and $96 \mathrm{~h}$ after the administration.
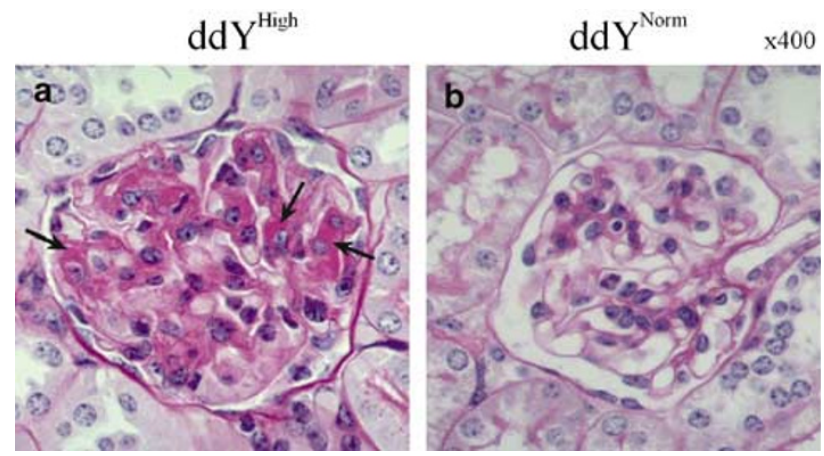

Figure 7 Pathological changes of the glomeruli of old ddY mice. The glomeruli of $\operatorname{ddY}^{\mathrm{High}}$ (a) and $\operatorname{ddY}^{\text {Norm }}$ (b) mice with PAS staining are shown. (a) The typical feature of IgAN, diffuse mesangial hypercellularity, mesangial PAS-positive deposits (indicated with arrows), and matrix proliferation, was observed. (b) Unchanged normal feature in the glomeruli of dd $\mathrm{Y}^{\mathrm{Norm}}$ mice was observed.

tion in this study is thought to have the same phenotype as that of the HIGA. However, the genetic basis that accounts for the elevation of serum $\operatorname{IgA}$ is still unknown.

As shown in Figure 5, we could not observe any qualitative differences in the structural properties of serum IgA between old $d d Y^{\text {High }}$ and $d_{d} Y^{\text {Norm }}$ populations. Also, molecular abnormalities of heavy 

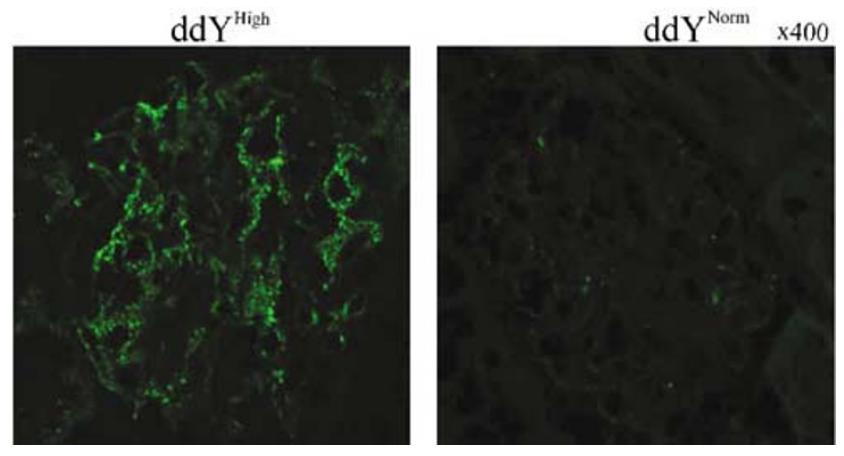

Figure $8 \mathrm{IgA}$ deposition in the glomeruli of old ddY mice. The IgA deposition in the glomeruli of $\operatorname{dd}^{\mathrm{High}}$ (a) and $\mathrm{dd}^{\mathrm{Norm}}(\mathbf{b})$ mice was analyzed by using confocal laser microscope after immunofluorescent staining (FITC) for IgA. (a) The granular pattern of IgA deposition was observed in the glomeruli of ddY $\mathrm{Y}^{\mathrm{High}}$ mice, which showed a decrease of pIgR expression in the kidney. (b) In contrast, few IgA deposition was detected in the glomeruli of $d d Y^{N o r m}$ mice, which had the normal expression of pIgR in the kidney.

and light chains of serum IgA molecules from $d d Y^{H i g h}$ and $d d Y^{N o r m}$ mice were not detected. Thus, the molecular alterations of $\operatorname{IgA}$ in the sera of dd $Y^{\text {High }}$ mice would not affect IgA clearance in mucosa. However, as demonstrated in Figure 6, the clearance rate of dimeric IgA in the serum was found to be slower in $d d Y^{\text {High }}$ than $d d Y^{\text {Norm }}$ mice. Moreover, both histological immunofluorescence analysis and semiquantitative RT-PCR examination revealed a decrease of pIgR expression in the epithelial cells of the kidney and the intestine in ddYHigh, but not ddYNorm, mice. Therefore, the age-dependent changes in the pIgR expression but not in the $\operatorname{IgA}$ structure seem to be a possible cause for the elevation of serum IgA.

The reason for the decrease of pIgR expression in the epithelial cells in mucosa of $\mathrm{ddY}^{\mathrm{High}}$ is still unknown. In rabbits, two forms of the SC (a high molecular weight form and a low molecular weight form) were reported to arise from differential RNA splicing. ${ }^{12}$ It is still unclear whether this type of mRNA splicing variation is one of the causes of decreased expression in mucosa of $d d \mathrm{Y}^{\mathrm{High}}$ mice. Nonetheless, it is likely that the age-dependent decrease of pIgR in mucosa and the anti-parallel increase of serum IgA in $d d Y^{\text {High }}$ mice may be associated directly with IgA deposition and with IgAN-like manifestations in $\mathrm{dd} \mathrm{Y}^{\mathrm{High}}$ mice.

Kaetzel et $a l^{13}$ have reported on active transport of immune complexes containing pIgA (pIgA-IC) across the epithelial cells by the same pIgR-dependent mechanism that normally applies to free pIgA. Several investigators ${ }^{14-18}$ have emphasized the importance of the pIgR-dependent system for transport of pIgA-IC, rather than the mononuclear phagocyte system, which mediates a major clearance pathway of immune complexes in circulation. Thus, the decreased pIgR expression observed in dd $\mathrm{Y}^{\text {High }}$ mice may potentially not only result in serum pIgA elevation but also serum pIgA-IC accumulation. Moreover, the fact that IgA accumulation in lamina propria of the intestinal mucosa has been shown in $\mathrm{pIgR}^{-1-}$ mice indicates that the impaired clearance of pIgA-IC and IgA deposition may occur in the pIgR-deficient glomeruli, as observed in $d d Y^{\text {High }}$ mice.

In the case of human IgAN, the defective clearance of dimeric IgA and/or IgA-IC has been demonstrated. ${ }^{19-21}$ In addition, Yasumori ${ }^{22}$ has represented the cases of decreased pIgR expression in the duodenum and impaired secretory-IgA-secretion in extra fluid in two of the 10 IgAN patients after duodenal biopsy. Therefore, decreased pIgR expression should also be found in some IgAN patients like dd $\mathrm{Y}^{\mathrm{High}}$ mice.

Taken together, the experiments in the present study suggest that systemic defects in pIgR expression may be a critical cause of inducing an accumulation of pIgA in the serum, followed by IgAN-like manifestation in dd $\mathrm{Y}^{\text {High }}$ mice. Identification and segregation of a highly disease-associated population in phenotypically heterogeneous ddY mice will allow us to carry out precise investigation for the pathogenesis of IgAN in mice and perhaps determine the mechanism of high concentration of serum pIgA in IgAN patients.

\section{Acknowledgement}

We are grateful to Dr T Iwase (Nihon University School of Dentistry) and $\mathrm{Dr} M$ Asano (Nihon University School of Dentistry) for providing pIgR cDNA-transfected cells and for valuable discussions, to Dr S Shimada (Yakult Central Institute) and Ms N Nagaoka (Yakult Central Institute) for providing anti-SC IgG and for competent technical assistance, and to Dr M Ishizaki (Nippon Medical School) and Dr M Hayashida (Nippon Medical School) for assistance in pathological techniques. We also thank Dr M Sugita (Nippon Medical School) for helpful suggestions and reading of the manuscript. This work was supported in part by grants from the Ministry of Education, Science, Sport, and Culture, from the Ministry of Health and Labor and Welfare, Japan, and from the Japanese Health Sciences Foundation.

\section{References}

1 Floege J, Feehally J. IgA nephropathy: recent developments. J Am Soc Nephrol 2000;11:2395-2403.

2 Wyatt RJ, Julian BA. Activation of complement in IgA nephropathy. Am J Kidney Dis 1988;12:437-442.

3 Emancipator SN, Lamm ME. IgA nephropathy: pathogenesis of the most common form of glomerulonephritis. Lab Invest 1989;60:168-183.

4 Noris M, Remuzzi G. IgA nephropathy: a stem cell disease? Kidney Int 1999;56:1964-1966. 
5 Conley ME, Cooper MD, Michael AF. Selective deposition of immunoglobulin A1 in immunoglobulin A nephropathy, anaphylactoid purpura nephritis, and systemic lupus erythematosus. J Clin Invest 1980;66:1432-1436.

6 Valentijn RM, Radl J, Haaijman JJ, et al. Circulating and mesangial secretory component-binding IgA-1 in primary IgA nephropathy. Kidney Int 1984;26:760-766.

7 Shimada S, Kawaguchi-Miyashita M, Kushiro A, et al. Generation of polymeric immunoglobulin receptordeficient mouse with marked reduction of secretory IgA. J Immunol 1999;163:5367-5373.

8 Imai H, Nakamoto Y, Asakura K, et al. Spontaneous glomerular IgA deposition in ddY mice: an animal model of IgA nephritis. Kidney Int 1985;27:756-761.

9 Klein-Schneegans AS, Kuntz L, Fonteneau P, et al. An indirect asymmetrical sandwich ELISA using antiallotype antibodies for the specific and quantitative measurement of mouse IgG2a of Igh-1b allotype. J Immunol Meth 1989;125:207-213.

10 Asano M, Saito M, Fujita H, et al. Molecular maturation and functional expression of mouse polymeric immunoglobulin receptor. J Immunol Meth 1998;214:131-139.

11 Miyawaki S, Muso E, Takeuchi E, et al. Selective breeding for high serum IgA levels from noninbred ddY mice: isolation of a strain with an early onset of glomerular IgA deposition. Nephron 1997;76:201-207.

12 Frutiger S, Hughes GJ, Fonck C, et al. High and low molecular weight rabbit secretory components. Evidence for the deletion of the second and third domains in the smaller polypeptide. J Biol Chem 1987;262:1712-1715.

13 Kaetzel CS, Robinson JK, Chintalacharuvu KR, et al. The polymeric immunoglobulin receptor (secretory component) mediates transport of immune complexes across epithelial cells: a local defense function for IgA. Proc Natl Acad Sci USA 1991;88:8796-8800.
14 Mannik M, Arend MP, Hall AP, et al. Studies on antigen-antibody complexes. I. Elimination of soluble complexes from rabbit circulation. J Exp Med 1971;133:713-739.

15 Cornacoff JB, Hebert LA, Smead WL, et al. Primate erythrocyte-immune complex-clearing mechanism. J Clin Invest 1983;71:236-247.

16 Waxman FJ, Hebert LA, Cosio FG, et al. Differential binding of immunoglobulin A and immunoglobulin G1 immune complexes to primate erythrocytes in vivo. Immunoglobulin A immune complexes bind less well to erythrocytes and are preferentially deposited in glomeruli. J Clin Invest 1986;77:82-89.

17 Russell MW, Mansa B. Complement-fixing properties of human IgA antibodies. Alternative pathway complement activation by plastic-bound, but not specific antigen-bound, IgA. Scand J Immunol 1989;30: 175-183.

18 Russell MW, Reinholdt J, Kilian M. Anti-inflammatory activity of human IgA antibodies and their Fab alpha fragments: inhibition of IgG-mediated complement activation. Eur J Immunol 1989;19:2243-2249.

19 Rifai A, Schena FP, Montinaro V, et al. Clearance kinetics and fate of macromolecular IgA in patients with IgA nephropathy. Lab Invest 1989;61:381-388.

20 Roccatello D, Picciotto G, Coppo R, et al. Clearance of polymeric IgA aggregates in humans. Am J Kidney Dis 1989;14:354-360.

21 Roccatello D, Picciotto G, Ropolo R, et al. Kinetics and fate of IgA-IgG aggregates as a model of naturally occurring immune complexes in IgA nephropathy. Lab Invest 1992;66:86-95.

22 Yasumori R. Measurement of secretory IgA in salivary juice and the localization of secretory IgA in duodenal mucosa in patients with IgA nephropathy. Nippon Jinzo Gakkai Shi 1990;32:171-181. 